\title{
Studi Simulasi Model Nested Logit dan Paired Combinatorial Logit pada Respon Multinomial
}

\author{
Jaka Nugraha \\ Program Studi Statistika UII \\ email : jk.nugraha@gmail.com
}

\begin{abstract}
Multinomial logit model (MNL) is based on independent irrelevant alternatives assumption. If there was a correlation, MNL would result bias estimator. Correlation among of choices could be accommodated by Nested logit Model (NL) and Paired Combinatorial Logit Model (PCL). This research discuss how NL and PCL model can be used for estimating parameters (regression coefficient and correlation) and comparing to MNL in discrete choice model. Correlation structure is tested nesting correlation and correlation overlap. Paramaters in the models are estimated using maximum likelihood method. Simulated data generated using software R.3.0.1. Based on simulations data with nested correlation, NL model more appropriate than do MNL. But on data with overlapping correlation, the maximum likelihood estimator is not unique.
\end{abstract}

Keywords : Multinomial logit, Nested logit, Paired Combinatorial Logit, maximum likelihood.

\begin{abstract}
ABSTRAK
Model Multinomial Logit (MNL) berdasarkan asumsi bahwa antar pilihan saling independen (independent irrelevant alternatives). Jika terdapat korelasi antar pilihan, maka MNL akan menghasilkan penaksir yang bersifat bias. Model Nested Logit (NL) dan Model Paired Combinatorial Logit (PCL) dapat mengakomudasi adanya korelasi tersebut. Penelitian ini membahas akurasi penaksir atas parameter koefisien regresi dan korelasi yang dihasilkan dari model MNL, NL dan PCL. Struktur korelasi yang diujikan adalah korelasi nested dan korelasi overlap. Penaksiran parameter dalam ketiga model mengunakan metode maksimum likelihood. Data simulasi dibangkitkan menggunakan software R.3.0.1. Berdasarkan hasil data simulasi, pada data nested model NL lebih akurat dibandingkan dengan model MNL. Sedangkan pada data overlap, estimasi menggunakan metode maksimum likelihood hasilnya tidak tunggal.
\end{abstract}

Kata-kata Kunci : Multinomial logit, Nested logit, Paired Combinatorial Logit, maximum likelihood.

\section{Pendahuluan}

Model Generalize Extreme Value (GEV) merupakan pengembangan dari MNL. Dalam MNL, diasumsikan memenuhi sifat independence from irrelevant alternatives (IIA) (Train, 2003). GEV disusun berdasarkan adanya korelasi antar alternatif pilihan. Model GEV yang telah banyak digunakan adalah NL dan
PCL. Model NL telah diaplikasikan dalam berbagai bidang seperti bidang energi, transportasi, perumahan, telekomonikasi (Train (1986), Forinash dan Koppelman (1993), Lee (1999)). Model GEV masih sangat terbatas pengembangan maupun aplikasinya, sehingga masih sangat terbuka untuk mendapatkan model-model GEV yang lebih powerfull (Train 
2003). Karlstrom (2001) telah menunjukkan fakta-fakta bahwa model GEV dapat disusun dengan menyesuaikan kondisi data yang ada.

Beberapa jenis model GEV yang telah dikembangkan untuk overlapping nest adalah model Cross-Nested Logit (CNLs) (Vovsha (1997), Bierlaire (1998), dan Ben-Akiva dan Bierlaire (1999)). Chu (1989) mengusulkan model Paired Combinatorial Logit (PCL). Jika terdapat $\mathrm{J}$ alternatif maka dapat disusun $\mathrm{J}-1$ nest. Wen dan Koppelman (2001) telah mengembangkan generalized nested logit (GNL), yang termasuk didalamnya model PCL.

Nugraha dkk (2009) telah menunjukkan berdasarkan data simulasi bahwa adanya korelasi antar pilihan pada model multinomial logit mengakibatkan estimator parameternya bias. Dalam penelitian ini dibahas model NL dan PCL untuk mengakomodasi adanya korelasi antar pilihan. Aplikasi model NL dan PCL pada data dengan struktur korelasi diketahui yang dibangkitkan secara simulasi dan dibandingkan hasilnya dengan model MNL. Struktur korelasi yang dibahas adalah korelasi nested dan korelasi overlapping. Pembangkitan data dan estimasi parameter disusun menggunakan program R.3.0.1.

\section{Model Nested Logit}

Model nested logit akan cocok ketika himpunan alternatif yang dijumpai pembuat keputusan dapat dibagi menjadi himpunan- himpunan bagian yang dinamakan nests. Sifat sifat dalam nested logit adalah

1. Untuk sebarang dua alternatif yang terletak pada nests yang sama memenuhi sifat IIA terhadap anternatif lain pada nest tersebut.

2. Sifat IIA tidak berlaku untuk dua alternatif yang terletak pada nest yang berbeda.

Misalkan himpunan alternatif $\mathrm{j}$ dapat dipartisi menjadi $\mathrm{K}$ bagian yang saling asing yaitu $B_{1}, B_{2}, \ldots, B_{K}$. Partisi ini dinamakan nest. Utilitas untuk pembuat keputusan i yang memilih alternatif $j$ dalam nest $B_{k}$ dapat dinotasikan sebagai

$$
\mathrm{U}_{\mathrm{ij}}=\mathrm{V}_{\mathrm{ij}}+\varepsilon_{\mathrm{ij}}
$$

$\mathrm{V}_{\mathrm{ij}}$ adalah faktor terobservasi yang merupakan fungsi dari $\mathrm{x}_{\mathrm{ij}} \quad\left(\mathrm{V}_{\mathrm{ij}}=\mathrm{V}\left(\mathrm{x}_{\mathrm{ij}}\right)\right)$ dan dinamakan representative utility. $\mathrm{x}_{\mathrm{ij}}$ adalah atribut pembuat keputusan (responden) ke-i. $\varepsilon_{\mathrm{ij}}$ merupakan faktor tidak terobservasi dalam utilitas. $\varepsilon_{\mathrm{i}}=\left(\varepsilon_{\mathrm{i} 1}, \ldots ., \varepsilon_{\mathrm{iJ}}\right)$ mempunyai distribusi kumulatif

$$
F\left(\varepsilon_{i}\right)=\exp \left(-\sum_{k=1}^{K}\left(\sum_{j \in B_{k}} \exp \left(-\frac{\varepsilon_{i j}}{\lambda_{k}}\right)\right)^{\lambda_{k}}\right)
$$

Distribusi ini merupakan jenis distribusi GEV (Heiss, 2002). Distribusi marginal untuk EKSAKTA Vol. 13 No. 1-2 Agustus 2013, 63-71 
masing-masing $\varepsilon_{\mathrm{ij}}$ adalah univariate extreme value. Diantara $\varepsilon_{\mathrm{ij}}$ yang terletak pada nest yang sama adalah saling berkorelasi, $\lambda_{\mathrm{k}}$ merupakan derajad independensi diantara alternatif yang terletak pada nest ke-k. Ukuran korelasi dapat dinyatakan sebagai

$$
\rho_{\mathrm{k}}=1-\lambda_{\mathrm{k}}
$$

Untuk dua alternatif yang terletak pada nest yang berbeda adalah saling independen atau

$$
\operatorname{Cov}\left(\varepsilon_{\mathrm{ij}}, \varepsilon_{\mathrm{im}}\right)=0
$$

untuk sebaran $\in \mathrm{B}_{\mathrm{k}}$ dan $\mathrm{m} \in \mathrm{B}_{1}$ dengan $\mathrm{k} \neq 1$.

Probabilitas memilih alternatif $j \in B_{k}$ adalah

$$
P_{i j}=\frac{\exp \left(\frac{V_{i j}}{\lambda_{k}}\right)\left(\sum_{j \in B_{k}} \exp \left(\frac{V_{i j}}{\lambda_{k}}\right)\right)^{\lambda_{k}-1}}{\sum_{l=i}^{k}\left(\sum_{j \in B_{l}} \exp \left(\frac{V_{i j}}{\lambda_{l}}\right)\right)^{\lambda_{k}}}
$$

Jika untuk setiap $\varepsilon_{\mathrm{ij}}$ adalah independen atau $\lambda_{\mathrm{k}}=1$ maka model nested logit ini akan sama dengan model logit standar.

\section{Model Overlapping Nest}

Dalam model nested logit di atas diasumsikan bahwa setiap alternatif hanya menjadi anggota satu nest. Dalam kenyataan sering dijumpai bahwa antar nest mempunyai interseksi (saling beririsan).
Nilai probalitas dalam model

PCL dapat dinyatakan sebagai

$$
P_{i j}=\frac{\sum_{j \neq j} \exp \left(V_{i j} / \lambda_{j r}\right)\left(\operatorname { e x p } \left(V_{i j} / \lambda_{j r}+\exp \left(V_{i j} / \lambda_{j r}\right)^{\lambda_{j r}-1}\right.\right.}{\sum_{k=1}^{J-1} \sum_{l=k+1}^{J}\left(\operatorname { e x p } \left(V_{i k} / \lambda_{k l}+\exp \left(V_{i l} / \lambda_{k l}\right)^{\lambda_{k l}}\right.\right.}
$$

dari pasangan sebanyak J-1, masing-masing pasangan mempunyai tingkat independensi sebesar $\lambda_{\text {jr }}$ (Koppelman dan Wen , 2000). Jika masing-masing independen $\left(\lambda_{\mathrm{jr}}=1 \quad \forall \mathrm{r}, \mathrm{j}\right)$ maka model PCL menjadi model logit standar.

Estimasi parameter $\beta$ dapat dilakukan dengan prosedur maksimum likelihood. Dengan mengasumsikan bahwa setiap keputusan antar individu saling independen maka probabilitas masing-masing individu dalam sampel memilih sebuah alternatif adalah

$$
L(\theta)=\prod_{i=1}^{n} \prod_{j}\left(P_{i j}\right)^{y_{i j}}
$$

Dengan $\mathrm{y}_{\mathrm{ij}}=1$ jika individu $\mathrm{i}$ memilih $\mathrm{j}$ dan nol jika memilih yang lainnya dan $\theta$ merupakan vektor parameter dalam model. Fungsi Log likelihood adalah

$$
L L(\theta)=\sum_{i=1}^{n} \sum_{j} y_{i j} \ln \left(P_{i j}\right)
$$

Penaksir $\theta$ adalah nilai $\theta$ yang memaksimumkan fungsi $L L(\theta)$. Parameter $\theta$ terdiri dari parameter koefisien $(\beta)$ dan parameter korelasi $(\rho)$ 


\section{Metode Simulasi}

Data diperoleh dari membangkitkan data dengan nilai korelasi antar alternatifnya ditentukan. Pengamatan dilakukan dengan mengambil model untuk tiga alternatif dengan memasukkan variabel atribut pembuat keputusan $\left(\mathrm{X}_{\mathrm{i}}\right)$ dan variabel atribut masing masing alternatif $\left(\mathrm{Z}_{\mathrm{ij}}\right)$. Variabel $\mathrm{X}_{\mathrm{i}}$ biasa disebut variabel demografi, misalnya penghasilan, jenis kelamin, asal daerah, jumlah anak. Sedangkan variabel $\mathrm{Z}_{\mathrm{ij}}$ misalkan untuk pilihan penggunaan alat tranportasi (Bus, mobil pribadi, sepeda motor) maka $\mathrm{Z}_{\mathrm{ij}}$ dapat berupa waktu tempuh, biaya. Model utilitasnya adalah

$$
\mathrm{U}_{\mathrm{ij}}=\mathrm{X}_{\mathrm{i}} \beta_{\mathrm{j}}+\mathrm{Z}_{\mathrm{ij}} \gamma+\varepsilon_{\mathrm{ij}}
$$

untuk $i=1,2, \ldots, n$ dan $j=1,2,3$.

$$
\begin{aligned}
& \mathrm{U}_{\mathrm{i} 1}=\beta_{01}+\mathrm{X}_{\mathrm{i}} \beta_{1}+\mathrm{Z}_{\mathrm{i} 1} \gamma+\varepsilon_{\mathrm{i} 1} \\
& \mathrm{U}_{\mathrm{i} 2}=\beta_{02}+\mathrm{X}_{\mathrm{i}} \beta_{1}+\mathrm{Z}_{\mathrm{i} 2} \gamma+\varepsilon_{\mathrm{i} 2} \\
& \mathrm{U}_{\mathrm{i} 3}=\beta_{03}+\mathrm{X}_{\mathrm{i}} \beta_{3}+\mathrm{Z}_{\mathrm{i} 3} \gamma+\varepsilon_{\mathrm{i} 3}
\end{aligned}
$$

Alternatif ke-tiga diambil sebagai base line, sehingga model terestimasinya menjadi

$$
\begin{aligned}
& \mathrm{U}^{*_{\mathrm{i} 1}}=\beta^{*_{01}}+\mathrm{X}_{\mathrm{i}} \beta_{13}+\mathrm{Z}_{\mathrm{i} 1} \gamma+\varepsilon_{\mathrm{i} 1} \\
& \mathrm{U}^{*_{\mathrm{i} 2}}=\beta^{*_{02}}+\mathrm{X}_{\mathrm{i}} \beta_{23}+\mathrm{Z}_{\mathrm{i} 2} \gamma+\varepsilon_{\mathrm{i} 2} ; \\
& \mathrm{U}^{*_{\mathrm{i} 3}}=\mathrm{Z}_{\mathrm{i} 3} \gamma+\varepsilon_{\mathrm{i} 3}
\end{aligned}
$$

dengan

$\beta_{13}=\beta_{1}-\beta_{3}, \beta_{23}=\beta_{2}-\beta_{3}, \beta^{*}{ }_{01}=\beta_{01}-\beta_{03}$ $\operatorname{dan} \beta^{*}{ }_{02}=\beta_{02}-\beta_{03}$.

Jadi terdapat 5 buah parameter yang akan diestimasi.
Untuk mendapatkan data multivariat normal dengan matrik kovariansi $\Sigma$ digunakan persamaan

$$
\varepsilon=\mathrm{L} \eta \text { dan } \Sigma=\mathrm{LL}^{\mathrm{t}}
$$

dimana $\eta \sim \mathrm{N}(0,1)$ dan $\mathrm{L}$ didefinisikan sebagai matrik segi tiga bawah dari faktor Cholesky. Program R menyediakan fasilitas membangkitkan data multivariat normal dalam library "MASS" dan program estimasi MLE terdapat dalam library "MicEcon" (Henningsen, 2007).

Data $\varepsilon_{\mathrm{i}}$ dibangkitkan dari distribusi multivariat normal, sementara itu MNL didasarkan pada distribusi nilai ekstrim, oleh karena itu diperlukan normalisasi sebagai berikut :

$$
\tilde{U}_{\mathrm{i}}=\mathrm{U}^{*}{ }_{\mathrm{i}} \cdot \sqrt{\pi^{2} / 6}=\mathrm{U}^{*}{ }_{\mathrm{i}} \cdot \sqrt{1.6}
$$

Persamaan (10) menjadi

$$
\tilde{U}_{\mathrm{i} 1}=\left(\beta^{*}{ }_{01}+\mathrm{X}_{\mathrm{i}} \beta_{13}+\mathrm{Z}_{\mathrm{i} 1} \gamma\right) \sqrt{1.6}
$$

$$
+\varepsilon_{\mathrm{i} 1} \sqrt{1.6}
$$

$\tilde{U}_{\mathrm{i} 2}=\left(\beta^{*}{ }_{02}+\mathrm{X}_{\mathrm{i}} \beta_{23}+\mathrm{Z}_{\mathrm{i} 2} \gamma\right) \sqrt{1.6}$

$$
+\varepsilon_{\mathrm{i} 2} \sqrt{1.6}
$$

$\tilde{U}_{\mathrm{i} 3}=\mathrm{Z}_{\mathrm{i} 3} \gamma \sqrt{1.6}+\varepsilon_{\mathrm{i} 3} \sqrt{1.6}$

Data dibangkitkan pada nilai parameter $\beta_{01}=2$, $\beta_{02}=, \beta_{03}=0.2, \beta_{1}=-3, \beta_{2}=-2, \beta_{3}=-1$ dan $\gamma=0.8$. Jadi $\beta^{*}{ }_{01}=1.8, \beta_{02}^{*}=0.8, \beta_{13}=-2, \beta_{23}=-1$ dan $\gamma=0.8$. Dengan adannya faktor pengali $\sqrt{1.6}$ 
maka estimator targetnya (yang diharapkan) adalah $\mathrm{B}_{01}=2.27684, \mathrm{~B}_{02}=1.011929, \mathrm{~B} 1=-$ adalah

$2.529822, \mathrm{~B} 2=-1.264911$ dan $\mathrm{C}=1.011929$.

Diambil 3 struktur kovariansi $\varepsilon_{\mathrm{i}}, \operatorname{Cov}(\varepsilon)$ $=\Sigma$ yaitu

$\Sigma_{\mathrm{A}}=\left(\begin{array}{lll}1 & 0 & 0 \\ 0 & 1 & 0 \\ 0 & 0 & 1\end{array}\right), \Sigma_{\mathrm{B}}=\left(\begin{array}{ccc}1 & 0 & 0 \\ 0 & 1 & 0.9 \\ 0 & 0.9 & 1\end{array}\right)$ dan

$\Sigma_{\mathrm{C}}=\left(\begin{array}{ccc}1 & 0.7 & 0.7 \\ 0.7 & 1 & 0.7 \\ 0.7 & 0.7 & 1\end{array}\right)$

$X_{\mathrm{i}} \sim \mathrm{NID}(0,1), Z_{\mathrm{ij}} \sim \mathrm{NID}(0,1)$ dan

$\varepsilon_{\mathrm{i}} \sim \mathrm{N}(\mathbf{0}, \Sigma)$

Model 1 dengan matrik kovariansi $\Sigma_{\mathrm{A}}$ sebagai model independen. Model 2 dengan matrik $\Sigma_{\mathrm{B}}$ sebagai model nested. Model 3 dengan matrik kovariansi $\Sigma_{\mathrm{C}}$ sebagai model overlapping nest.

Agar parameter dalam model terestimasi, dengan model tersebut di atas dibutuhkan sampel minimal $\mathrm{n}=500$ (Nugraha, 2007). Replikasi pada masing-masing kovariansi dilakukan sebanyak 30 kali.

Misal untuk $\mathrm{j}=1,2,3$ yang terbagi ke dalam 2 nest. Alternatif $j=2,3$ masuk dalam satu nest. Distribusi kumulatif untuk model NL adalah

$$
F\left(\varepsilon_{i}\right)=\exp \left(-\left[\exp \left(-\frac{\varepsilon_{i 1}}{\lambda 1}\right]^{\lambda 1}-\left(\exp \left(-\frac{\varepsilon_{i 2}}{\lambda_{2}}\right)+\exp \left(-\frac{\varepsilon_{i 3}}{\lambda_{2}}\right)\right)^{\lambda_{2}}\right)\right.
$$

$$
\begin{gathered}
P_{i 1}=\frac{\left(\exp \left(\frac{V_{i 1}}{\lambda_{1}}\right)\right)^{\lambda_{1}}}{\left(\exp \left(\frac{V_{i 1}}{\lambda_{1}}\right)\right)^{\lambda_{1}}+\left(\exp \left(\frac{V_{i 2}}{\lambda_{2}}\right)+\exp \left(\frac{V_{i 3}}{\lambda_{2}}\right)\right)^{\lambda_{2}}} \\
P_{i 2}=\frac{\exp \left(\frac{V_{i 2}}{\lambda_{2}}\right)\left(\exp \left(\frac{V_{i 2}}{\lambda_{2}}\right)+\exp \left(\frac{V_{i 3}}{\lambda_{2}}\right)\right)^{\lambda_{2}-1}}{\left(\exp \left(\frac{V_{i 1}}{\lambda_{1}}\right)\right)^{\lambda_{1}}+\left(\exp \left(\frac{V_{i 2}}{\lambda_{2}}\right)+\exp \left(\frac{V_{i 3}}{\lambda_{2}}\right)\right)^{\lambda_{2}}} \\
P_{i 3}=\frac{\exp \left(\frac{V_{i 3}}{\lambda_{2}}\right)\left(\exp \left(\frac{V_{i 2}}{\lambda_{2}}\right)+\exp \left(\frac{V_{i 3}}{\lambda_{2}}\right)\right)^{\lambda_{2}-1}}{\left(\exp \left(\frac{V_{i 1}}{\lambda_{1}}\right)\right)^{\lambda_{1}}+\left(\exp \left(\frac{V_{i 2}}{\lambda_{2}}\right)+\exp \left(\frac{V_{i 3}}{\lambda_{2}}\right)\right)^{\lambda_{2}}}
\end{gathered}
$$

dengan

$$
\begin{aligned}
& \mathrm{V}_{\mathrm{i} 1}=\left(\beta^{*}{ }_{01}+\mathrm{X}_{\mathrm{i}} \beta_{13}+\mathrm{Z}_{\mathrm{i} 1} \gamma\right) \sqrt{1.6} ; \\
& \mathrm{V}_{\mathrm{i} 2}=\left(\beta^{*}{ }_{02}+\mathrm{X}_{\mathrm{i}} \beta_{23}+\mathrm{Z}_{\mathrm{i} 2} \gamma\right) \sqrt{1.6} ; \\
& \mathrm{V}_{\mathrm{i} 3}=\mathrm{Z}_{\mathrm{i} 3} \gamma \sqrt{1.6}
\end{aligned}
$$

Nilai probalitas dalam model PCL dapat dinyatakan sebagai

$$
\begin{aligned}
& P_{i 1}=\frac{A^{\lambda_{12}-1} \cdot \exp \left(V_{i 1} / \lambda_{12}\right)+B^{\lambda_{13}-1} \cdot \exp \left(V_{i 1} / \lambda_{13}\right)}{A^{\lambda_{12}}+B^{\lambda_{13}}+C^{\lambda_{23}}} \\
& P_{i 2}=\frac{A^{\lambda_{12}-1} \cdot \exp \left(V_{i 2} / \lambda_{12}\right)+C^{\lambda_{23}-1} \exp \left(V_{i 2} / \lambda_{23}\right)}{A^{\lambda_{12}}+B^{\lambda_{13}}+C^{\lambda_{23}}} \\
& P_{i 3}=\frac{B^{\lambda_{13}-1} \cdot \exp \left(V_{i 1} / \lambda_{13}\right)+C^{\lambda_{23}-1} \exp \left(V_{i 2} / \lambda_{23}\right)}{A^{\lambda_{12}}+B^{\lambda_{13}}+C^{\lambda_{23}}}
\end{aligned}
$$

dengan

$$
\begin{aligned}
& A=\left[\exp \left(V_{i 1} / \lambda_{12}\right)+\exp \left(V_{i 2} / \lambda_{12}\right)\right] \\
& B=\left[\exp \left(V_{i 1} / \lambda_{13}\right)+\exp \left(V_{i 3} / \lambda_{13}\right)\right] \\
& C=\left[\exp \left(V_{i 2} / \lambda_{23}\right)+\exp \left(V_{i 3} / \lambda_{23}\right)\right]
\end{aligned}
$$


Program disusun dalam dua tahap, estimator untuk parameter korelasi antar pertama adalah proses membangkitkan data alternatifnya (Gambar .2).

dengan distribusi dan struktuk kovariansi tertentu. Kedua, adalah melakukan estimasi parameter pada masing-masing model.

\section{Hasil dan Pembahasan}

Dalam bab ini dibahas hasil estimasi parameter menggunakan tiga model yaitu MNL, NL dan PCL. Model MNL menghasilkan 5 parameter, model NL dan PCL menghasilkan 6 parameter. Uji statistika untuk masing-masing parameter tidak ditampilkan disini karena semua estimator yang dihasilkan adalah signifikan. Untuk menguji kecocokan model digunakan nilai log-likelihood.

\section{Model MNL dan Model NL}

Probabilitas pilihan $\left(\mathrm{P}_{\mathrm{ij}}\right)$ pada Model MNL dan Model NL berbentuk persamaan tertutup. Fungsi likelihood kedua model merupakan fungsi yang mempunyai titik maksimum tunggal, sehingga dengan MLE untuk masing-masing parameter juga tunggal. Waktu yang diperlukan untuk mendapatkan penaksir juga relatif cepat.

Pada data dengan tingkat korelasi nol, nilai likelihood pada model MNL adalah relatif sama dengan nilai like-lihood pada model NL (Gambar 1.). Demikian juga estimasi dari kelima parameter, hasilnya juga relatif sama. Pada model NL, kita juga mendapatkan

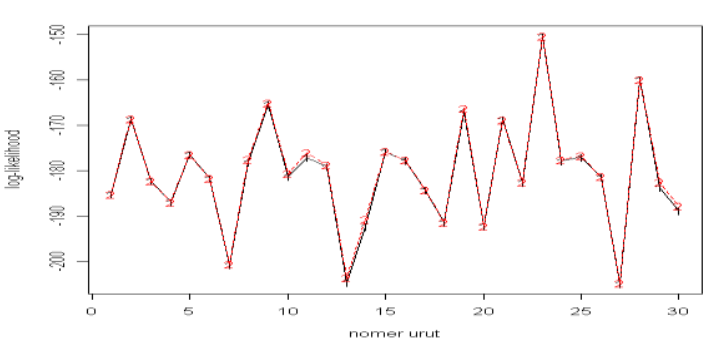

Gambar 1. Grafik log-likehood model 1.

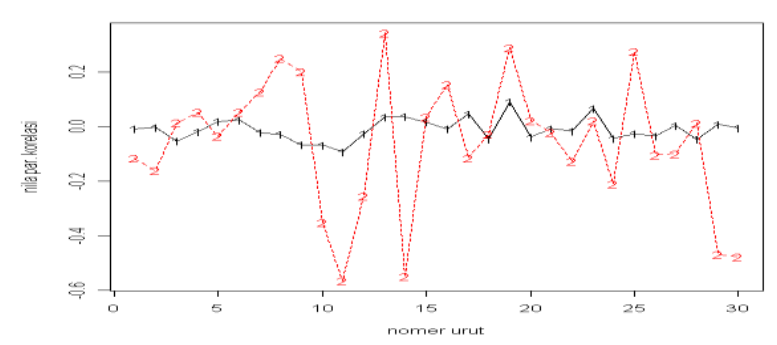

Gambar 2. Grafik korelasi pada model 1

Pada Gambar (2) merupakan grafik korelasi respon dua dan respon tiga $\left(r_{23}\right)$ pada korelasi aktual dan korelasi prediksi. Perbedaan kedua nilai tidak signifikan, dari pengujian diperoleh nilai p-value 0.2511. Dapat disimpulkan bahwa model Nested dapat memprediksi dengan baik parameter korelasi.

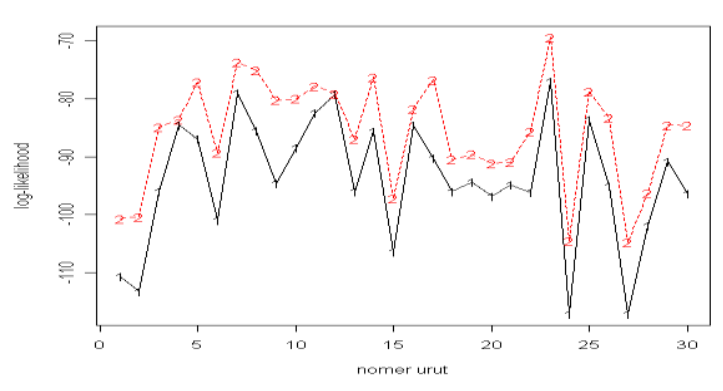

Gambar 3. Nilai Log likelihod model 2. EKSAKTA Vol. 13 No. 1-2 Agustus 2013, 63-71 
Pada data dengan tingkat korelasi antara alternatif 2 dan alternatif 3 sama dengan 0.9, nilai log likelihood pada model MNL lebih kecil dibanding dengan model NL (Gambar. 3). Dapat disimpulkan model NL lebih tepat untuk memprediksi model yang memuat korelasi.

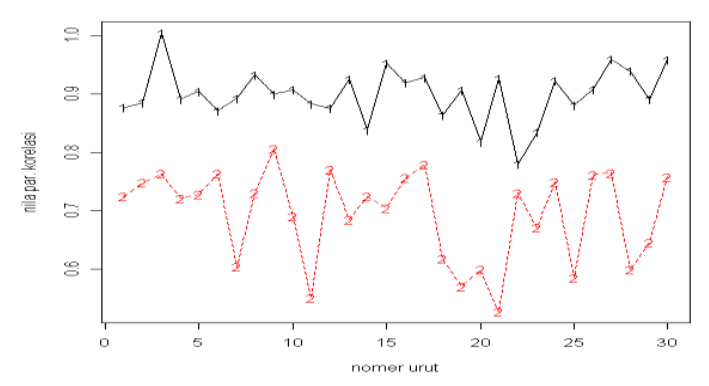

Gambar 4. Korelasi pada model 2

Dengan model NL, kita dapat memprediksi besarnya korelasi antar respon, walaupun nilai estimatornya masih bias. Gambar (4) menunjukkan selisih antara korelasi aktual dan korelasi prediksi pada tingkat korelasi alternatif 2 dan alternatif 3 sebesar 0,9 . Estimasi parameter yang lain, menunjukan bahwa selisih estimator model MNL terhadap nilai parameter target adalah lebih besar dibandingkan dengan selisih estimasi parameter model NL terhadap nilai parameter targetnya. Bias pada model NL lebih kecil dibanding bias pada model MNL.

\section{Model PCL}

Fungsi Log likelihood pada model PCL merupakan fungsi yang tidak global concave (cekung bawah) sehingga sulit mencari titik global maksimum. Nilai awal yang beda menghasilkan nilai MLE yang berbeda. Dari gambar (5), jika $\lambda \rightarrow-\infty$ maka fungsi likelihoodnya $\rightarrow 0$, sehingga nilai MLE tidak diperoleh. Untuk mengatasi keadaan ini, perlu dilakukan pembatasan terhadap nilai $\lambda$, yaitu $\lambda>0$. Selanjutnya untuk mendapatkan estimator dalam model PCL, perlu memvariasi nilai awal dari $\lambda$ dengan nilai antar $0 \mathrm{~s} / \mathrm{d} 1$.

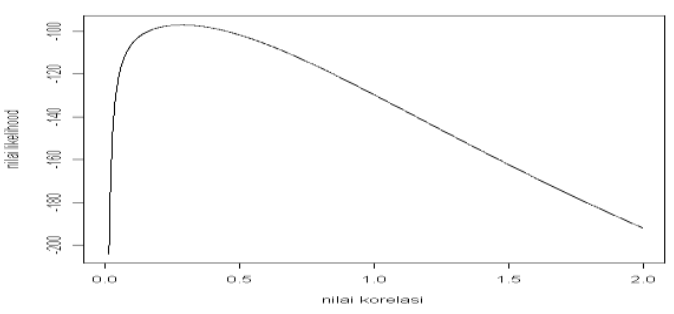

Gambar 5. Grafik fungsi likelihood dengan parameter $\lambda$.

Cara ke dua untuk mengatasi keadaan tersebut diatas, agar MLE dapat diperoleh adalah dengan menggabungkan langkahlangkah estimasi dalam model MNL dan model PCL. Langkah-langkahnya adalah sebagai berikut :

1. Estimasi parameter menggunakan model MNL, hasilnya dinyatakan dengan $\hat{\beta}_{1}$

2. Estimasi parameter korelasi $\lambda$ dengan $\beta=\hat{\beta}_{1}$ menggunakan model overlaping logit, hasil dinyatakan dengan $\hat{\lambda}$

3. Estimasi parameter korelasi $\beta$ dengan $\lambda=\hat{\lambda}$ menggunakan model overlaping logit, hasil dinyatakan dengan $\hat{\beta}_{2}$. 
Sehingga estimator parameternya adalah

$$
\hat{\theta}=\left(\hat{\beta}_{2}, \hat{\lambda}\right)
$$

Selanjutnya Gambar 6. nilai $\log$ likelihood pada model 3 menunjukkan bahwa model MNL dan model overlaping logit tidak jauh berbeda.

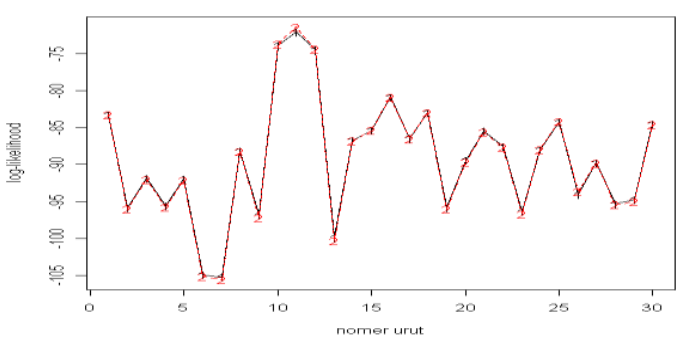

Gambar 6. Grafik log likelihood model 3

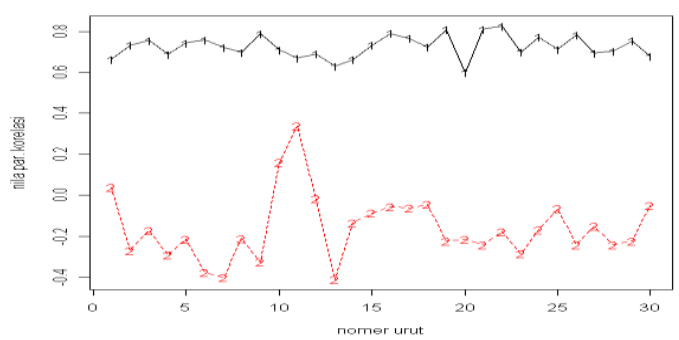

Gambar 7. Grafik nilai korelasi model 3

Estimasi parameter korelasi pada model 3 menggunakan model overlapping memberikan hasil yang tidak cukup baik. Demikian juga estimasi parameter yang lain, model PCL tidak lebih baik dibanding dengan model MNL.

Secara teori, model PCL dapat mengukur korelasi antar nest. Namun demikian berdasarkan data simulasi, model PCL tidak mengahasilkan penaksir yang lebih baik dibandingkan dengan model MNL. Li dan
Ouyang (2009) telah mengembangkan model PCL dengan memodifikasi parameter nya secara terpadu sedemikian hingga parameternya lebih sederhana..

\section{Kesimpulan}

Dalam model DCM, jika antar respon memiliki struktur korelasi nested maka model NL lebih sesuai dibanding dengan model MNL. Model NL dapat mengurangi bias dan dapat mengestimasi korelasi pada masing-masing nest.

Jika respon memiliki struktur overlapping, estimator pada model PCL tidak tunggal. Pengambilan penduga awal yang berbeda akan menghasilkan estimator yang berbeda. Untuk mengatasi hal ini dapat dilakukan dengan cara mencoba beberapa penduga awal untuk parameter $\lambda$ dengan nilai antar $0.5 \mathrm{~s} / \mathrm{d} 1.5$ dan memilih salah satu hasil estimasi ini. Cara kedua adalah menggabungkan model MNL dan model PCL.

\section{Saran-saran}

Dari hasil penelitian ini disarankan kepada para peneliti yang akan mengaplikasikan model DCM, sebaiknya menggunakan model NL dari pada model MNL.

Untuk penelitian lebih lanjut, dapat dilakukan pengamatan terhadap model DCM yang lain seperti model mixed logit. Masalah lain yang belum banyak mendapat perhatian 
para peneliti adalah pengembangan model DCM

pada respons multinomial multivariat

\section{Daftar Pustaka}

Ben-Akiva,M. dan M. Bierlaire, 1999, 'Discrete choice methods and their applications in short term travel decisions', in R. Hall, ed., The Handbook of Transportation Science, Kluwer, Dordrecht, The Netherlands, pp. 5-33.

Bierlaire, M., 1998, Discrete choice models, in M. Labbe, G. Laporte, K. Tanczos, and P. Toint, eds., Operations Research and Decision Aid Methodologies in Traffic and Transportation Management, Springer-Verlag, Heidelberg, Germany, pp. 203-227.

Chu, C., 1989, A paired combinational logit model for travel demand analysis, Proceedings of Fifth World Conference on Transportation Research 4, 295-309.

Forinash, C. and F. Koppelman, 1993, Application and interpretation of nested logit models of intercity mode choice, Transportation Research Record 1413, 98-106.

Heiss, F., 2002, Structural Choice Analysis with Nested Logit Models, STATA Journal $2: 227-252$.

Henningsen, A., 2007, The micEcon Package, http://www.r-project.org/. diakses tanggal 10 Desember 2013

Karlstrom, A., 2001, Developing generalized extreme value models using the Piekands representation theorem', Working Paper, Infrastructure and Planning, Royal Institute of Technology, Stockholm, Sweden.
Koppelman, F. dan C. Wen, 2000, The paired combination logit model: Properties, estimation and application, Transportation Research B 34, 75-89.

Nugraha J., Haryatmi S., Guritno S., 2009, Pengaruh Korelasi Antar Respon pada Model Multinomial Logit, Jurnal Matematika dan Sains (JMS), Vol. 14 No. 3, FMIPA-ITB.

Lee, B., 1999, Calling patterns and usage of residential toll service under selfselecting tariffs, Journal of Regulatory Economics 16, 45-82.

Li, J. dan Ouyang, J., 2009, A Modified Paired Combinatorial Logit Route Choice Model with Unified Parameter, Logistics, 367503680.

Train, K.,1986, Qualitative Choice Analysis, MIT Press, Cambridge, MA.

Train, K., 2003, Discrete Choice Methods with Simulation, UK Press, Cambridge

Vovsha, P.,1997, The cross-nested logit model: Application to mode choice in the Tel Aviv metropolitan area, Conference Presentation, $76^{\text {th }}$ Transportation Research Board Meetings, Washington.

Wen, C.-H. dan Koppelman, F., 2001, 'The generalized nested logit model', Transportation Research B 35, 627-641. 